\title{
Práticas discursivas e função enunciativa na constituição do sujeito quilombola
}

\section{Discursive practices and enunciative function in the construction of the quilombola identity}

\author{
Claudemir SOUSA \\ Universidade Federal do Maranhão (UFMA) \\ Ilza Galvão CUTRIM \\ Universidade Federal do Maranhão (UFMA)
}

\begin{abstract}
RESUMO: Nosso objetivo neste artigo é analisar a constituição discursiva do sujeito quilombola. Discutimos as diferentes posições ocupadas pelo sujeito quilombola por meio da análise dos mecanismos discursivos que arquitetam uma letra de música composta pelos habitantes da comunidade quilombola Jamary dos Pretos (Turiaçu - Maranhão), em comemoração aos seus 170 anos. Para tanto, mobilizamos o aporte teórico da Análise do Discurso (AD), particularmente a arqueogenealogia de Michel Foucault, e autores do campo da História e dos Estudos Culturais. Este trabalho se caracteriza por uma abordagem qualitativa do corpus, que tem como marca a descrição e a interpretação.
\end{abstract}

PALAVRAS-CHAVE: Discurso. Enunciado. Sujeito quilombola. Identidade

ABSTRACT: This article analyzes the discursive constitution of the quilombola subject. We will discuss the different positions occupied by the quilombola subject by the analysis of the discursive mechanisms that design a lyric composed by the inhabitants of the quilombola comunity Jamary dos Pretos (Turiaçu - Maranhão), in celebration of the 170 years of that community. Therefore, we mobilize the theoretical framework of Discourse Analysis (A D), particularly Michel Foucault's archeogenealogy, authors from the field of History and Cultural Studies. This work is characterized by a qualitative approach of the corpus, which is marked by a description and interpretation.

KEYWORDS: Discourse. Statement. Quilombola subject. Identity

\section{Introdução}

A Análise do Discurso (doravante AD) surge em meados da década de 1960, na França, como uma forma de abordar a política por meio da linguagem. A AD se caracteriza como um campo de entremeio, e suas raízes estão fincadas em uma tradição intelectual europeia que, nos anos 60, articulou aportes teóricos da linguística (releitura de Saussure feita por Pêcheux), ao materialismo histórico (releitura de Marx por Althusser), à psicanálise (releitura de Freud por Lacan), e a uma certa prática escolar de explicação de textos ${ }^{1}$. Assim, a $\mathrm{AD}$ emerge no entrecruzamento do Materialismo Histórico, da Linguística e da Teoria do Discurso, todos atravessados por um

\footnotetext{
${ }^{1}$ Para uma discussão sobre a constituição da AD indicamos a leitura de Maldidier (1997), para quem a fundação da $\mathrm{AD}$ se trata de uma dupla fundação por Jean Dubois e Michel Pêcheux, concepção que é refutada por Courtine (2005).
} 
subjetivismo de ordem psicanalítica que insere nos estudos discursivos o inconsciente (FERNANDES, 2007).

Dada a multiplicidade de campos dos saberes com os quais dialoga, a AD é palco de embates teóricos, principalmente entre Foucault e Pêcheux. Os diálogos e duelos (GREGOLIN, 2004a) entre esses dois autores oferecem infinitas possibilidades para análises de discursos que circulam em diversas materialidades.

Para operar com o discurso é necessário destacar que ele não é texto, não é fala, nem tão pouco língua, apesar de poder ter elementos linguísticos em sua existência material (FERNANDES, 2007). O discurso, para Foucault (2008), expressa-se em unidades menores: o enunciado, que deve ser analisado em conjunto, produzido na dispersão de acontecimentos. A concepção de enunciado como unidade de análise é salutar para se empreender um trabalho no campo da Análise do Discurso.

No capítulo "Definir o enunciado", do livro Arqueologia do saber, Foucault (2008, p. 98) afirma que o enunciado tem um modo singular de existência. O enunciado "não é, pois, uma estrutura (isto é, um conjunto de relações entre elementos variáveis, autorizando assim um número talvez infinito de modelos concretos)".

Para diferenciar o enunciado de uma estrutura, Foucault o distingue da frase, da proposição e do ato de fala, pois estes, guardadas as devidas especificidades, tratam-se de estruturas linguísticas, lógicas e/ou analíticas, ao passo que o enunciado, para Foucault (2008, p. 98) é:

uma função de existência que pertence, exclusivamente, aos signos, e a partir da qual se pode decidir, em seguida, pela análise ou pela intuição, se eles "fazem sentido" ou não, segundo que regra se sucedem ou se justapõem, de que são signos, e que espécie de ato se encontra realizado por sua formulação (oral ou escrita). [...] ele [o enunciado] não é em si mesmo uma unidade, mas sim uma função que cruza um domínio de estruturas e de unidades possíveis e que faz com que apareçam, com conteúdos concretos, no tempo e no espaço.

No capítulo seguinte, Foucault (2008) afirma que "a função enunciativa" se relaciona a quatro características intrínsecas ao enunciado, a partir das quais se pode determinar a existência de um enunciado em uma dada materialidade. São elas: o referencial, a posição-sujeito, o campo associado e a existência material.

$\mathrm{O}$ referencial diz respeito às condições de possibilidades que determinam as regras de existência do enunciado. Para Foucault (2008), o enunciado não depende de um referente que permita atribuir sentido a uma proposição e conferir-lhe um valor de verdade. "A montanha de ouro está na Califórnia", segundo ele, consiste em uma afirmação absurda, caso esteja relacionada à realidade. Por outro lado, essa mesma afirmação adquire nova consistência em um romance, pois este abre espaço à fantasia. Neste caso, o sentido relaciona o enunciado ao seu espaço de correlação, ou seja, ao conjunto de domínios que permite o aparecimento de objetos no enunciado.

Assim, para além da proposição, que está relacionada a um referente, o enunciado liga-se a um referencial. Este, por sua vez, não se constitui de "coisas", de "fatos", de "realidades" ou de "seres", mas de leis de possibilidade, de regras de existência para os objetos que aí se encontram nomeados, designados ou escritos, para as relações que aí se encontram afirmadas ou negadas. Enfim, o enunciado define as possibilidades de aparecimento e de delimitação do que dá à frase seu sentido, à proposição seu valor de verdade. (FOUCAULT, 2008, p. 104).

Outra característica da função enunciativa é sua relação a um campo associado. $\mathrm{O}$ enunciado liga-se a uma série de enunciados que o precedem e aos quais se refere, 
atualizando-os, ao mesmo tempo em que está associado a enunciados que o sucedem e lhe abrem um futuro. Desta forma, a função enunciativa "não pode se exercer sem a existência de um domínio associado". (FOUCAULT, 2008, p.109)

Nesse sentido, "não há enunciado em geral, enunciado livre, neutro e independente; mas sempre um enunciado fazendo parte de uma série ou de um conjunto, desempenhando um papel no meio dos outros, neles se apoiando e deles se distinguindo". (FOUCAULT, 2008, p. 113-114) O enunciado não é determinado por um sujeito que fala, pois antecede o próprio ato da elocução. É através do domínio de memória que os enunciados se sucedem, se ordenam, na medida em que se afirmam ou se opõem.

Foucault ainda destaca que o enunciado tem uma existência material. Isso significa dizer que o enunciado necessita de uma materialidade que lhe determine um tempo e um espaço, sua individualização e, assim, possibilite observar sua transformação. Segundo o autor (2008, p. 116), "A enunciação é um acontecimento que não se repete; tem uma singularidade situada e datada", mas que permite reconhecer, sob a forma geral de uma proposição, um mesmo enunciado. $\mathrm{O}$ enunciado pode ser repetido, mas a enunciação jamais se repete. Uma mesma afirmação em momentos históricos diferentes pode não constituir um mesmo enunciado. Os sonhos realizam desejos é um enunciado que se distingue em Platão e em Freud porque é a relação dessa afirmação com outras proposições a ela associadas que determina suas condições de formação e de transformação. (FOUCAULT, 2008)

Por último, destacamos a característica do enunciado, que é sua relação com um sujeito. Segundo Foucault (2008), o sujeito do enunciado não é um elemento gramatical, como uma primeira pessoa presente em uma frase. Existem enunciados que não admitem primeira pessoa em sua estrutura material, mas isso não significa que não tenham um sujeito.

O sujeito tampouco se confunde com um autor, enquanto indivíduo real que produziu a frase, pois o autor está relacionado à noção de origem e, portanto, ligado a uma intencionalidade que permitiu o ordenamento das palavras. $\mathrm{O}$ "autor", enquanto elemento emissor, não é idêntico ao sujeito do enunciado porque as leis de possibilidade que determinam o enunciado são anteriores à enunciação.

A posição de sujeito é definida como um lugar determinado por "condições de individualização do sujeito". Um único e mesmo indivíduo "pode ocupar, alternadamente, em uma série de enunciados, diferentes posições e assumir o papel de diferentes sujeitos". (FOUCAULT, 2008, p. 107).

O enunciado é, pois, concebido por Foucault como função enunciativa que define textos como acontecimentos discursivos produzidos por um sujeito, em um lugar institucional, determinado por regras sócio-históricas que definem e possibilitam a emergência dos discursos na sociedade.

Após essas considerações, empreendemos nossos esforços no intuito de compreender que práticas discursivas definem as condições de exercício da função enunciativa de identidades quilombolas em Jamary dos Pretos, comunidade quilombola localizada no município de Turiaçu, Maranhão, a partir da análise de uma música composta para homenagear os 170 anos dessa comunidade.

\section{A posição sujeito do enunciado e a concepção de identidade}

Conforme ressalta Foucault (2008), o sujeito do enunciado é historicamente determinado. Esse sujeito sofre mudanças de um enunciado a outro e a função enunciativa pode ser exercida por diferentes sujeitos. Daí que um único e mesmo 
indivíduo pode ocupar, em uma série de enunciados, diferentes posições e assumir o papel de distintos sujeitos - pai, professor, político, consumidor etc. O sujeito é aqui visto, portanto, como uma categoria móvel, fluida.

O sujeito discursivo deve ser considerado sempre como social, apreendido em um espaço coletivo. "Trata-se de um ser sujeito não fundado em uma individualidade, em um eu individualizado e sem existência em um espaço social e ideológico, em um dado momento histórico e não em outro. A voz desse sujeito revela o lugar social" (FERNANDES, 2004, p. 33).

Importa também dizer sobre o sujeito na $\mathrm{AD}$ que este não é homogêneo, pois sua voz é constituída pela voz de outros sujeitos. É essa concepção de sujeito como móvel que põe a $\mathrm{AD}$ em relação com os Estudos Culturais. O sociólogo Stuart Hall (2006), ao investigar a identidade dos sujeitos na modernidade tardia, ressalta que as velhas identidades, que por um longo período foram responsáveis pela estabilidade do mundo social, estão em declínio e estão promovendo uma fragmentação do indivíduo moderno, fazendo com que a ideia de unidade seja esquecida.

À pergunta sobre o que estaria deslocando as identidades culturais nacionais no fim do século XX, ele responde: "um complexo de processos e forças de mudança, que, por conveniência, pode ser sintetizado sob o termo 'globalização'" (HALL, 2006, p. 67). O sociólogo nos mostra essa transformação histórica do sujeito a partir de três concepções: o sujeito do Iluminismo, cujas ações eram regidas por um racionalismo; o sujeito sociológico, formado na relação com outras pessoas com as quais apreende os valores, sentidos e símbolos - a cultura - dos mundos que ele/ela habita e o sujeito pósmoderno, "composto não de uma única, mas de várias identidades, algumas vezes contraditórias ou não resolvidas" (HALL, 2006, p. 12).

Levando em conta que a produção discursiva feita por sujeitos, inseridos em uma contingência histórica, resulta em efeitos de sentidos e que estes são a forma de apreensão da realidade pelo sujeito, consideramos os discursos como categorias móveis, que estão sempre em movimento, sofrem transformações e acompanham as transformações sociais e políticas de toda a vida humana. Tal qual o sujeito, a identidade não é fixa, está sempre em produção. Transformada continuamente, encontra-se em um processo ininterrupto de construção e se caracteriza por mutações. $\mathrm{O}$ discurso, dispositivo de enunciação, é o principal veículo da produção de identidades (FOUCAULT, 2001).

Um estudo sobre o discurso exige que o deixemos aparecer na complexidade que lhe é peculiar. Nesse sentido, torna-se necessário vê-lo não como um conjunto de signos, que carrega este ou aquele significado repleto de intenções. Os discursos são feitos de signos, claro, "mas o que fazem é mais que utilizar esses signos para designar coisas. É esse mais que os tornam irredutíveis à língua e ao ato da fala. É esse mais que é preciso fazer aparecer e que é preciso descrever". (FOUCAULT, 2008, p. 56) Esse mais faz do discurso uma prática que relaciona a língua com outra coisa - uma prática discursiva. Conforme já destacamos, o conceito de discurso em Foucault compreende um conjunto de práticas que demandam análise.

Como essa discussão proposta por Foucault (2008) se relaciona com os trabalhos no campo da Análise do Discurso que se situam na confluência do discurso com a história? A tarefa da Análise do Discurso é procurar na materialidade do discurso, no conjunto de imagens, gestos, expressões, modos de circulação dos discursos, dentre outros, os efeitos de sentidos criados pelos sujeitos, considerando as condições históricas de produção que envolvem o discurso. Os fenômenos sociais têm existência na História, daí a necessidade de investigar os discursos a partir de um momento histórico social de produção. 
Essas condições sofreram transformações, as quais serão manifestas nas produções discursivas, lugares de cruzamento de vozes e discursos outros que antecedem o mesmo, acentuando-se a fragmentação dos sujeitos, a heterogeneidade constitutiva dos discursos. Conforme ressalta Veyne (2008), tudo é histórico. E a densidade histórica é apanhada pelos discursos, na articulação entre discurso e história.

O discurso, o social e o histórico são também lugares de manifestação da memória na construção de identidades.

\title{
3. A Articulação entre História, Memória, Discurso e construção de identidades
}

A história tradicional, organizada em narrativas sequenciais de acontecimentos hierarquizados, concebia os indivíduos como atores pouco conscientes em uma totalidade. A consciência de si era intermediada pela narração histórica. Essa concepção é repensada por Foucault (2007; 2008), que vê as mudanças históricas como processo atravessado pela dispersão e descontinuidade, em que todos os sujeitos estão envolvidos. O cotidiano e a história são vistos diferentemente da proposta tradicional, portanto. Interessa agora a descontinuidade, ou seja, a quebra com a história tradicional, com a relação de causa e efeito.

Outra questão relevante destacada por Foucault (2008) são as mudanças operadas na escrita historiográfica pela Escola dos Annales, que se preocupa não mais em revelar e explicar o real, mas em desconstruí-lo enquanto discurso. Com os Annales o historiador amplia seu olhar sobre as fontes e com isso há uma mudança na concepção de documento. Em princípio, o documento era, sobretudo, o texto e havia uma preocupação com sua autenticidade. É certo que "não há história sem documento", mas é preciso "tomar a palavra 'documento' no sentido mais amplo, documento escrito, ilustrado, transmitido pelo som, pela imagem, ou de qualquer outra maneira", destaca um dos historiadores da Nova História, Jacques Le Goff. (1994, p. 539).

Conforme Foucault (2008, p.14), precisa ficar clara para o historiador a distinção entre o documento e o monumento.

\begin{abstract}
em nossos dias, a história é o que transforma os documentos em monumentos, e o que, onde se decifravam traços deixados pelos homens, onde se tentava reconhecer em profundidade o que tinha sido, desdobra uma massa de elementos que se trata de isolar, de agrupar, de tornar pertinentes, de estabelecer relações, de constituir conjuntos.
\end{abstract}

Segundo essa visão, tudo agora é importante; não há mais distinção entre documento e monumento. Os documentos devem ser todos lidos como monumento e o trabalho do historiador é contextualizar os documentos, desestruturando sua construção e analisando suas condições de produção (LE GOFF apud GREGOLIN, 2004, p. 24).

Em nossa análise, elegemos um documento (uma música composta por moradores da comunidade de Jamary dos Pretos) visto como monumento, pois produz sentidos ao ser fruto de construções de sujeitos inseridos em uma determinada contingência histórica.

Importa pensar os acontecimentos sem tentar recuperar sua origem, já que esta se dispersou no tempo e ocorre descontinuamente. Mas como lidar com um objeto de estudo se todas as bases materiais tentam apontar para uma origem?

Vale então considerar que essa origem é ilusória e está ligada a outro momento. Os acontecimentos dispersos agora serão agrupados historicamente, reagrupados e 
relacionados a um só princípio organizador (FOUCAULT, 1995). Assim, explica Fernandes (2007, p. 23), "a referência à história se faz necessária, pois trata-se dos sentidos produzidos no discurso de acordo com as condições de produção histórico sociais peculiares à existência dos sujeitos".

A produção de sentidos a partir das condições históricas e sociais traz à baila uma concepção sociológica de sujeito, na medida em que considera a subjetividade como decorrente de uma construção social. Essa concepção, no entanto, entrelaça-se a outras concepções de sujeito, considerando-se a heterogeneidade constitutiva do discurso e do sujeito (AUTHIER-REVUZ, 1998).

Diante da relação paradoxal entre perenidade e mudança, o homem irá eleger símbolos que delimitem os traços de sua identidade, numa busca pela afirmação e legitimação da memória, entendida como a seleção de fatos que merecem ser relembrados. Essa seleção, segundo Foucault (2006), é feita por meio de uma economia do poder que elege o que pode/deve ser apresentado ao sujeito. Na escolha dos elementos que serão dignos de lembrança, alguns acontecimentos são selecionados, em prol de outros, como mais importantes.

A memória é um mecanismo poderoso para que uma comunidade mantenha vivos seus traços identitários. Segundo Davallon (1999), para que haja memória, é preciso que o acontecimento ou o saber registrado saia da indiferença, deixe o domínio da insignificância. $\mathrm{O}$ acontecimento deve conservar uma força para depois deixar sua impressão. $O$ autor ainda acrescenta que o acontecimento lembrado necessita reencontrar sua vivacidade, sendo necessária sua reconstrução a partir de dados e de noções comuns aos diferentes membros da comunidade social.

Conforme já destacamos, analisaremos como o sujeito quilombola é constituído discursivamente em Jamary, a partir de um acontecimento discursivo e da análise da função enunciativa. As perguntas que nos movem são: que elementos são representativos de uma identidade quilombola em Jamary dos Pretos, na contemporaneidade; que acontecimento discursivo é marcante nessa construção, e que memórias fortalecem a edificação dessa identidade?

O acontecimento discursivo que perpassa o corpus selecionado para nossa análise se dá em torno da busca pela posse da terra onde se localiza Jamary dos Pretos. Esse acontecimento é, inicialmente, marcado pela luta de pesquisadores de movimentos negros, que chegam a Jamary nos anos 90 e promovem um movimento de conscientização identitária junto aos moradores do lugar.

Os trabalhos dos pesquisadores resgatam a história e promovem uma valorização da memória de antigos moradores e, consequentemente, um sentimento de pertencimento ao lugar. Esse resgate é fundamental na constituição de suas identidades.

A luta por território está diretamente ligada à luta por identidade. O território é caracterizado por suas singularidades, por ser fonte de identificação. Configura-se como espaço em que agentes individuais e coletivos expressam suas tradições, sua história e cultura partilhadas, centrada num domínio de parentesco. A Fundação Cultural Palmares, ao assumir uma visão antropológica, refere-se aos territórios habitados por "remanescentes de quilombos" como "sítios historicamente ocupados por negros e que são possuidores de conteúdos culturais de valor etnográfico" (BRASILEIRO \& SAMPAIO, 2002, p. 84).

A experiência histórica dos quilombos se traduz em manifestações culturais que se expressam em festas e danças como o Tambor de Crioula. Em Jamary, um dos elementos representativos da identidade quilombola é o tambor de crioula, forma de expressão de matriz afro-brasileira que envolve dança circular, canto e percussão de tambores, praticado especialmente em louvor a São Benedito. 
Para comemorar os 170 anos de Jamary foi composta uma música em cuja letra sobressai-se o reconhecimento à figura de Ivan Rodrigues Costa (1962-2011), militante do movimento negro e pesquisador do Centro de Cultura Negra do Maranhão. Analisamos essa composição. A chegada de historiadores a Jamary é assim narrada:

Aqui em Jamary quando Ivan chegou/

Quem vivia como escravo se libertoul

Foi pelo Sindicato que se descobriul

E a nossa liberdade ressurgiu.

Em 94, começou a Associação de Moradores/

Quando a carta de despejo aqui chegou/

Foi aí que a nossa luta continuou.

Ivan e seus companheiros sempre lutando/

E dona Ana Amélia nos ajudando/

No quilombo Jamary quando começou/

Formaram a Associação de Moradores.

Ivan que hoje já mora com o senhor/

Mas Ivo e Ana Amélia não nos deixoul

Ivan Costa quando veio nos reuniul

Para lutar contra o racismo no Brasil.

Foi aí que se juntou com toda igreja

Pra lutar até vencer esta peleja

170 anos de história e de poder

Quilombo Jamary, parabéns pra você $(2 x)$.

$\mathrm{Na}$ análise dessa música, o sujeito da enunciação ancora-se em um acontecimento constantemente rememorado: a chegada a Jamary dos pesquisadores Ivan Costa, Ivo Fonseca Silva e Ana Amélia Campos Mafra. Os efeitos de sentidos que emergem desse acontecimento vão construir uma identidade marcada por uma resistência racial. Em fins da década de 1970 e início dos anos 80, quilombo é sinônimo de "resistência negra". (ARRUTI, 2003).

Esse acontecimento é marcado logo na primeira estrofe com o dêitico aqui, que demarca um espaço em particular na enunciação: Jamary. Essa demarcação exclui do discurso outros espaços que poderiam emergir da interpretação; em Jamary houve uma mudança que produziu na comunidade um movimento de conscientização de si e essa mudança foi provocada pelos três pesquisadores.

A chegada e permanência de Ivan Costa, Ana Amélia Campos Mafra e Ivo Fonseca - destacada no primeiro verso da terceira estrofe com uma locução verbal no gerúndio "Ivan e seus companheiros sempre lutando" (grifamos) - representa para a comunidade local a tomada de consciência de si, uma ideia de territorialidade, que se ancora num conceito contemporâneo de quilombola, que não está ligado a uma 
identidade ancestral ou mesmo a tradições africanas, mas sim, a uma consciência de si enquanto pertencente a um território que deve ser seu e para isso é preciso lutar pela posse da terra. A chegada dos pesquisadores é um acontecimento que, sempre relembrado, permanece vivo na memória da comunidade, pois se tornou parte de uma história comum a todos.

No verso "Quem vivia como escravo se libertou", o tempo verbal "vivia", no pretérito imperfeito, indica uma ação simultânea, inacabada. Conforme Fiorin (2002, p.158), o imperfeito apresenta os fatos como simultâneos, formando um quadro contínuo, ou melhor, vinculado ao mesmo momento de referência pretérito. $\mathrm{O}$ sentido da palavra escravo, nesse enunciado, pode não estar vinculado, necessariamente, à escravidão tradicional, mas à ausência de consciência de sua condição de cidadão, de pertencimento ao lugar Jamary. Em outras palavras, antes da chegada de Ivan Costa e demais pesquisadores, Jamary era visto como um espaço geográfico, herança dos antepassados; após sua chegada passa a ser o espaço da luta, da libertação, da consciência de si. O enunciado Quem vivia como escravo se libertou mantém relações específicas com história, política, cultura, gerando uma cadeia de enunciados ulteriores a ele. Conforme certas condições sociais, políticas e históricas, que se inscrevem no âmbito do domínio associado em que o enunciado se acomoda, há certa vontade de verdade que incide sobre a existência e a manutenção do enunciável.

No caso em específico, essa vontade de verdade encontra-se no plano das lutas por liberdade e igualdade e se acomoda em práticas discursivas que lhe dão regularidade.

No terceiro verso da primeira estrofe "Foi pelo Sindicato, onde se descobriu", não há na materialidade linguística um complemento para o verbo "descobrir", mas a historicidade comprova a existência de um documento de registro do local onde se localizam as terras de Jamary. Nesse enunciado, assim como na terceira estrofe, a figura do Sindicato é marcada como um elemento importante na busca pela territorialidade e também como parte integrante de uma identidade quilombola.

O enunciado "E a nossa liberdade ressurgiu", que completa o enunciado anterior, indica uma conscientização coletiva, marcada pelo pronome "nossa". Essa conscientização ocorre com o apoio da organização sindical. Assim como o Sindicato, a Associação de Moradores também é algo que passa pela via da legalidade, do coletivo. Há uma consciência coletiva do ser quilombola, uma unificação das lutas, possibilitada por essa entidade, que o faz por vias legais e graças a um trabalho de conscientização dos sujeitos. Há, na esteira de Hall, uma identidade sociológica, na medida em que a consciência de territorialidade é algo que se realiza somente após uma tomada de conscientização desenvolvida por um grupo de pesquisadores que chegam a Jamary nos anos noventa. A identidade é uma construção coletiva.

Conforme destaca Almeida (1996, p. 11), as novas dimensões sobre o significado atual de quilombo têm como ponto de partida "situações sociais específicas e coetâneas, caracterizadas, sobretudo, por instrumentos político-organizativos, cuja finalidade precípua é a garantia da terra e a afirmação de uma identidade própria".

No enunciado "Quando a carta de despejo aqui chegou", o dêitico "quando" sinaliza um segundo acontecimento: a ameaça de expulsão que a comunidade de Jamary sofria, mas esse momento também é um acontecimento que marca uma mudança, uma consciência de luta. A carta de despejo de que fala o enunciador foi um dos principais motivos para o início de uma luta pela terra que resultou na criação da Associação de Moradores e, consequentemente, no fortalecimento da comunidade.

Em "Foi aí que a nossa luta continuou", novamente temos uma ideia de identidade coletiva, com a instalação do pronome pessoal "nós". O dêitico "aí" (no 
sentido de "foi nesse momento") situa um novo momento de consciência que se dá pela ameaça da perda do território.

Considerando que não existe enunciado que não suponha outros, a memória exerce um papel fundamental na relação entre o enunciado e o arquivo. O enunciado, em sua relação com o arquivo, é aquilo que surge com valor de acontecimento em meio a um espaço colateral povoado por outros enunciados. Esse espaço colateral é denominado por Foucault de "campo associado", formado pela série de formulações em que o enunciado se inscreve e pela série das formulações em que o enunciado repete, modifica, adapta, se opõe ou propicia a possibilidade ulterior (sua consequência, sequência natural ou réplica).

Nessa esteira, os discursos que permeiam as lutas têm sentidos itinerantes, pois resultam de práticas discursivas diversas e partem de diferentes lugares enunciativos. $\mathrm{Na}$ letra da música o sujeito fala do lugar de quem se reconhece enquanto um "guerreiro", enquanto um membro de Sindicato e de Associação de Moradores, que luta por manter sua identidade. Em "Foi aí que a nossa luta continuou", há uma retomada de um enunciado muito comum, que é dito como palavra de ordem em certas cenas enunciativas, mas os sentidos são outros, não se repetem. $\mathrm{O}$ sujeito desse enunciado se diferencia, por exemplo, de um integrante de um partido político de esquerda que toma como palavra de ordem "a luta continua".

O enunciado se repete, mas o momento de enunciação transforma as formações discursivas de cada enunciador produzindo novos sentidos, a partir de um novo campo de utilização, que não é o de um partidário político, mas sim um membro de um sindicato e de uma associação de moradores, relacionando o enunciado ao seu espaço de correlação. O tempo que se instala, por meio do uso de verbo no passado ("a nossa luta continuou"), expressa a duratividade pelo emprego do verbo no pretérito imperfeito e apresenta uma formação discursiva da resistência. Graças ao domínio de memória esse enunciado se sucede, na medida em que se afirma/opõe.

Vale lembrar que o sujeito da enunciação ancora-se num acontecimento constantemente rememorado: a chegada dos pesquisadores. Os efeitos de sentidos que emergem desse acontecimento vão construir uma identidade assinalada também por uma resistência racial e resistência pela organização sócio-política.

O destaque à figura de Ivan Costa se dá por meio de uma economia de poder, que só é possível pelo efeito de memória. Mesmo com seu falecimento, ressaltado na quarta estrofe, o que é destacado pelo enunciador é a militância de Ivan Costa ("Ivan Costa quando veio nos reuniu/Para lutar contra o racismo no Brasil") e seu legado de luta, comemorado nos cento e setenta anos de Jamary ("170 anos de história e de poder/Quilombo Jamary parabéns pra você").

Segundo Halbwachs (1950 apud DAVALLON, 1999, p. 25), a memória implica no "que ainda é vivo na consciência do grupo para o indivíduo e para a comunidade". É a grandiosidade desse acontecimento e dos que o sucederam que o fazem digno de rememorização porque é relevante para o grupo. A identidade vai, pois, sendo construída por meio da memória que emerge em determinados momentos, sempre lembrando que em cada emergência há a produção de um novo sentido.

\section{Algumas Considerações}

Discutir identidade na pós-modernidade é questionar a nossa história, construída dia a dia, mostrando-nos a liquidez dos acontecimentos que nos marcam enquanto sujeitos fragmentados, possuidores de identidades fluidas, inseridos em um mundo cada vez mais globalizado. A produção das identidades tem no discurso, enquanto dispositivo 
de enunciação, seu principal veículo, sendo um efeito de sentido produzido no e pelo discurso.

Os mecanismos discursivos que tecem a música analisada revelam em sua materialidade enunciados que se entrecruzam com a história e a memória de uma coletividade agenciando sua(s) identidade(s).

A chegada de pesquisadores a Jamary é um acontecimento discursivo que encontra sua força na memória da comunidade e lhe ajuda a produzir uma nova consciência de si, criando saberes e hábitos que modificaram toda uma tradição que parecia sólida: uma identidade marcada por uma ideia de ancestralidade ganha novos contornos, sendo marcada, na contemporaneidade, por uma luta pela terra.

O sujeito do enunciado constrói sua identidade numa relação de alteridade, ou seja, na relação com outros sujeitos com os quais apreende valores, sentidos e símbolos dos mundos que habita, ao mesmo tempo em que se torna flexível quando confrontado com outra realidade - a consciência de si, de territorialidade. A identidade é uma construção em curso e os sujeitos estão vivendo um eterno processo de identificação que se desenvolve e se transforma com a História.

\section{Referências}

ALMEIDA, Alfredo Wagner B. de. Quilombos: sematologia face a novas identidades. In: Frechal - terra de preto, quilombo reconhecido como reserva extrativista. São Luís: SMDDH/CCN - PVN. 1996.

ARRUTI, José Maurício P. A. O quilombo conceitual: para uma sociologia do artigo 68 do ADCT. In: Texto para discussão: Projeto Egbé - Territórios negros (KOINONIA), 2003.

AUTHIER-REVUS, J. Palavras incertas - as não coincidências do dizer. Campinas: Editora da Unicamp, 1998.

BRASILEIRO, Sheila; SAMPAIO, José Augusto. Sacutiaba e Riacho de Sacutiaba: uma comunidade negra rural no oeste baiano. In: O'DWYER, Eliane Cantarino. (Org.). Quilombos: identidade étnica e territorialidade. Rio de Janeiro: Editora FGV, 2002.

COURTINE, J.J. A estranha memória da Análise do Discurso. In: INDURSKY, Freda; FERREIRA, Maria Cristina Leandro (Org.). Michel Pêcheux e a Análise do Discurso: uma relação de nunca acabar. São Carlos: Claraluz, 2005, p. 25-32.

DAVALLON, J. Imagem, uma arte de memória? In: ACHARD, P. et. al. Papel da memória. Campinas: Pontes, 1999.

FERNANDES, Cleudemar Alves. Análise do Discurso: reflexões introdutórias. Goiânia: Trilhas Urbanas, 2007.

Cleudemar A.; SANTOS, João B. C. (Orgs.). Análise do Discurso: unidade e dispersão. São Paulo: EntreMeios, 2004. 
FERREIRA, Aurélio Buarque de Holanda. Novo dicionário da língua portuguesa. Rio de Janeiro: Objetiva, 2000.

FIORIN, José Luiz. As astúcias da enunciação: as categorias de pessoa, espaço e tempo. São Paulo: Ática, 2002.

FOUCAULT, M. A arqueologia do saber. Trad. Luis Felipe Baeta Neves. 2a. Ed. Rio de Janeiro: Forense-Universitária, 2008.

A ordem do Discurso. São Paulo: Edições Loyola, 2007.

Outros espaços. In: MOTA, M. B. (Org.). Michel Foucault e a Estética: literatura e pintura, música e cinema. Rio de Janeiro: Forense Universitária, 2001. v. 3, p. 411-422.

As palavras e as coisas. São Paulo: Martins Fontes, 1995.

GREGOLIN, Maria do Rosário. Foucault e Pêcheux na Análise do Discurso: diálogos e duelos. São Carlos, SP: Claraluz, 2004a.

Michel Foucault: O Discurso na Trama da História. In: FERNANDES, Cleudemar Alves; SANTOS, João Bosco Cabral dos (Orgs.). Análise do discurso: unidade e dispersão. Entre Meios, Uberlândia, 2004b.

HALL, Stuart. A identidade cultural na pós-modernidade. Rio de Janeiro: DP\&A, 2006.

LE GOFF, Jacques. História e memória. Campinas: Editora da UNICAMP, 1994.

MALDIDIER, Denise. Elementos para uma história da Análise do Discurso na França. In: ORLANDI, Eni Puccinelli. Gestos de leitura: da história no discurso. Trad. Bethânia S. C. Mariani (et al.). 2. ed. Campinas, SP: Editora da UNICAMP, 1997.

VEYNE, Paul. Foucault, sa pensée, sa personne. Paris: Albin Michel, 2008. 